\section{Lack of consultant expansion}

\section{CCHMS chairman responds to Mr Paige's claim}

The chairman of the National Health Service Management Board, Mr Victor Paige, gave evidence to the House of Commons Public Accounts Committee on 10 June. He responded to a report published by the Comptroller and Auditor General that improved patient care and better value for money could result from a consultant based NHS. It was reported in The Times that Mr Paige had told the select committee that the proposals would mean a reduction in the average number of junior doctors supporting each consultant. According to the newspaper report the Public Accounts Committee was told that hospital consultants were "thwarting attempts to improve health care and achieve savings by opposing the promotion of junior doctors to their ranks."

Dr Maurice Burrows, chairman of the Central Committee for Hospital Medica Services, has responded to this report as he believes that it would be damaging if the evidence given by the Department of Health was "not in direct accord with the main reason behind the currently unsatisfactory expansion of consultant posts." His letter to Mr Paige is set out here.

"CCHMS, representing all hospital consultants, and every other body involving national groups of consultants, believe that the health service needs more cosultants. It is not true to allege that 'hospital consultants are thwarting attempts to improve health care and achieve savings by opposing the promotion of junior doctors to their ranks.' What many consultants do feel is a growing frustration that sound proposals for additional consultant posts (and indeed, on occasion, replacement ones) are unable to be processed further or implemented by district authorities. In these days money is not always available, but there may be an underlying fear in the authority that new consultants, because of their innovative nature, may lead authorities with straitened resources into further financial difficulties.

"There is evidence that an initial expansion of consultants could take place without alteration of facilities. This first stage could be followed by a second and it will be necessary to examine what structural improvements will be required to accommodate the extra patients to be treated-for example, in enlarged outpatient departments and new operating theatres.

"Care must continue to be taken to preserve a balanced cadre of consultantsbetween 'prime movers' and the service specialties. What had been a barrier to consultant expansion across the board in years gone by-lack of trained doctors in some specialties-has virtually disappeared.

"At one time regional health authorities were responsible both for the establishment of consultant posts and for their financing. The financing has been gradually devolved to districts and this devolution has added to the difficulties in implementing a satisfactory consultant expansion. District health authorities have many local pressures and insistent groups, which demand an allocation of resources and it is arguable that the almost complete devolution of spending money to districts has inhibited the wider and less immediate view as to how resources should be spent and is in fact a hindrance to an adequate consultant expansion.

"I hope it will be possible to reassure us that the Public Accounts Committee were aware that consultants do believe an improved service to patients would result from an increase in their number and have said so on many occasions."

\section{CVCP warns about parity for clinical staff}

The Review Body for Doctors' and Dentists' Remuneration recommended an increase of over $6 \%$ (15 June, p 1836). This has been accepted by the government although implementation was delayed for two months to 1 June. The cash limited grant to universities, however, includes provision for salary in creases of only 3\%. In 1979 the Clinical Academic Staff Salaries Committee was set up to consider how to translate the salary arrangements for NHS doctors to clinical academic staff and parity has been maintained since 1968. The BMA had written to Sir Keith Joseph, Secretary of State for Education, in May reminding him of the principle of parity and he had replied that he could give no undertaking to adjust the recurrent grant to universities if the award was more than allowed for when the grant had been decided (15 June, $p$ 1842).

Although the Committee of Vice Chancellors and Principals wishes to continue the principle of parity, it has said that there are "serious financial impediments" to doing so. The chairman of the committee, Mr Maurice Stock, is writing to ministers telling them that the universities are unable to undertake discussions in the Clinical Academic Staff Salaries Committee on the level of clinica academic salaries until they know the outcome of approaches that have been made to both the Department of Education and Science and the DHSS for comparable funding for universities to enable them to pay their clinical academic staff similar increases to those that the NHS will pay its staff.

\section{Civil Service medical officers}

The BMA/Institution of Professional Civil Servants committee has been re-established and met on 6 June, chaired by Dr C J Bolt, who is chairman of the BMA's Civil Service medical officers group committee. The new arrangements for collaborating between the BMA and the institution were published on 4 May ( $p$ 1368). Remuneration, retirement age, superannuation, milage allowances, annual leave, and the future of the Artificial Limb and Appliance Service were discussed at the meeting on 6 June. Both sides hoped that the meeting would lead to improved cooperation between the two organisations for the benefit of Civil Service doctors and dentists.

\section{BMA membership at 31 May 1985}

General practitioners

Senior hospital doctors

Junior hospital doctors

Community medicine and community health doctors

Civil Service doctors

Armed forces doctors

Occupational health

Medical academic staff

Members in practice but not identifiable by group

Total in practice

17633

2131

Retired niembers

Total UK membership

Total overseas membership

\section{Higher fees and new guidance note on fees from BMA}

The BMA's Fees Guide has been replaced by a guidance note-Fees for part time medical services. The guide has a series of supplements, each of which so far as possible is self contained, thus obviating the need to supply information not directly relevant to the individual member's request. The guidance note, a list of supplements with an index, and individual supplements are available only to members and only from local BMA offices.

Details of the following increased fees may now be obtained from local BMA offices:

- Certain fees payable under the Costs in Criminal Cases (Allowances) Regulations, which are laid down by the Lord Chancellor's Department, are to rise with effect from 3 June 1985. For example, the fee for the examination to determine fitness for detention centre training is rising from $£ 14$ to $£ 14 \cdot 60$. (Members are asked to quote FS33B when applying for details.)

- Fees for surgery examinations done in surgery and reports based on medical records requested by the National Coal Board are to go up, backdated to 1 January 1985. The new fees are $£ 14.60$ and $£ 9.20$ respectively. (Members are asked to quote FS14 when applying for details.)

\section{Correction}

Review body evidence committee

In the list of members of the BMA's review body evidence committee (15 June, $p$ 1840) the representatives of the Central Committee for Community Medicine and Community Health were omitted. They were Dr David Miles, chairman of the CCCMCH (district medical officer); Dr Kathleen Dalzell, chairman of the community health doctors subcommittee (senior clinical medical officer); and Dr John Sarginson, chairman of the CCCMCH negotiating subcommittee (district medical officer)

Published by the Proprietors, THE BRITISH MEDICAL ASSOCIATION, Tavistock Square, London WC1H 9JR, and printed in Great Britain by George Pulman and Sons Limited of London and Bletchley. Typesetting by Bedford Typesetters Limited, Bedford.

Registered as a Newspaper. 